\title{
A SURVEY OF RAMP AND STAIR USE AMONG OLDER ADULTS
}

\author{
Kimberly Graves Wolfinbarger and Randa L. Shehab \\ School of Industrial Engineering \\ University of Oklahoma \\ Norman, Oklahoma
}

\begin{abstract}
Forty-three community-dwelling adults aged 57 to 95 participated in survey exploring characteristics of ramp use by older ambulant people. Twenty-three respondents said they ascended ramps instead of stairs most of the time, and 14 said they ascended ramps some of the time. Similar numbers were reported for descent. Overall, respondents felt less fatigued, less likely to trip, and more comfortable when using ramps rather than stairs for ascending one level. When descending one level, balance, tripping, and comfort were the strongest determinants of ramp use. Respondents indicated that descent was more problematic, particularly in regard to balance and tripping. The presence of handrails often determined the choice of route. Results from this survey provided the basis for an experiment evaluating the abilities of older people to traverse ramps of various slopes. The ADA Accessibility Guidelines implicitly assume that a ramp accommodates everyone. This study indicates that entrances should have both ramps and stairs.
\end{abstract}

\section{INTRODUCTION}

The population of the United States is growing older. In 1998, the 34.4 million Americans aged 65 and over accounted for $12.7 \%$ of the population, the highest percentage in history. This proportion is expected to increase to $20 \%$, or 69 million people, by 2030 (U.S. Department of Health and Human Services, 1996 and 1999). In recent years, more older adults have begun living alone (U.S. DHHS, 1996), a phenomenon due in part to the rise in popularity of retirement communities and assisted living centers. Thirty-one percent of elderly people lived alone in 1990; of those aged 85 and older, $47 \%$ lived alone (Hawes, Rose, and Phillips, 1999).

Architectural features which accommodate the needs of elderly users help make independent living possible by facilitating the use of public and residential facilities and reducing the likelihood of injury. For example, because stairs pose problems for many older people, alternative means of access such as elevators, escalators, and ramps are useful. Often, however, these means are not specifically designed for use by the elderly.

Ramps have become more common in the United States since the 1990 passage of the Americans with Disabilities Act (ADA). The ADA Accessibility Guidelines (ADAAG) were based largely upon ANSI $117.1(1980,1986)$ and work by Steinfeld, Schroeder, and Bishop (1979). For the most part, the ADAAG standard for ramp design was written to accommodate wheelchair users, the group generally considered to have the most difficulty with architectural barriers (Sanford, Duncan, Guerette, Mace, Ostroff, Gupta, and Jo, 1994). In an extensive literature review of studies related to ramp use, Sanford et al. (1994) found that only a few had examined ramp use by elderly people or people with ambulatory difficulties.

The ADAAG define a ramp as " any part of an accessible route with a slope greater than 1:20;" that is, one centimeter of rise for every $20 \mathrm{~cm}$ of run (United States Access Board,
1990; ADAAG Section 4.8.1). Ramps in new construction may have a maximum slope of $1: 12$; those in existing buildings where this slope is infeasible may have a slope no steeper than 1:10 for a maximum rise of $15.25 \mathrm{~cm}(6 \mathrm{in})$ and $1: 8$ for a maximum rise of $7.6 \mathrm{~cm}$ ( $3 \mathrm{in})$. The ADAAG allow a maximum run of $9 \mathrm{~m}(30 \mathrm{ft})$ for slopes between $1: 12$ and $1: 15$

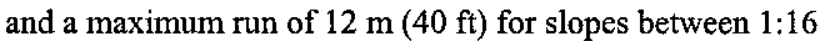
and 1:20, inclusive. These guidelines were designed primarily to aid wheelchair propulsion and to prevent wheelchairs from tipping backward (Sanford et al., 1994).

\section{BACKGROUND}

Several methods have been used to evaluate people's abilities to negotiate ramps. Steinfeld et al. (1979) asked wheelchair users, users of walking aids, and nondisabled people to traverse $12 \mathrm{~m}$ ramps of three grades, $1: 12,1: 16$, and 1:20. Among other measures, they recorded speed and distance traveled. All wheelchair users were able to ascend the ramp at the 1:20 slope, but only half were able to complete ascent at the 1:12 slope. Ninety-eight percent of the ambulant participants with mobility impairments were able to ascend the $12 \mathrm{~m}$ ramp at the 1:12 slope. For ramps used by the general population, the authors recommended a maximum slope of

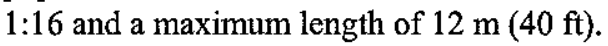

Sanford, Story, and Jones (1997) evaluated the effects of ramp slope on the abilities of 171 people of various ages and impairments to traverse $9 \mathrm{~m}$ ramps. The youngest subjects were under six years of age, and the oldest subjects were over 75. All participants had problems with mobility, and most used an assistive device. Rate of travel, distance traveled, location and duration of rest stops, and physiological measures were evaluated during ascent and descent of six slopes between 1:20 and 1:8. Almost all of the participants were able to traverse the entire $9 \mathrm{~m}$ ramp at each slope. Manual wheelchair users had more trouble; $85 \%$ were able to complete ascent at the standard ADAAG slope of 1:12. "None 
of the subjects exhibited significant cardiovascular exertion" (p. 31), but walker users reported greater levels of difficulty during both ascent and descent than the other groups. While the speed of all groups generally declined with increasing ramp slope, the decline was insignificant for the ambulant participants.

Couch (1992) observed ramp use by mall shoppers. The entrance to a department store was about $1.5 \mathrm{~m}$ above the mall concourse and was accessible via a ramp or either of two stairways. The ramp, located between the two stairways, was $27.5 \mathrm{~m}$ long and curved upward to the second level. Sixty-five percent of the people leaving or entering the store used the ramp, and more people used the ramp for descent than for ascent. While no observations were noted regarding the physical abilities of the stair users, a small number of ramp users had obvious physical impairments. Five used wheelchairs, and 19 had ambulatory difficulties.

Very few studies have examined the biomechanics of ramp use. The ramps used in a study by Corlett, Hutchinson, DeLugan, and Rogozenski (1972) had much steeper grades than those encountered in public buildings. The ramps were constructed by laying boards over stairs, and their slopes ranged from 1:1.7 to $1: 5.7$. The experimenters found that the physiological cost of climbing the ramps was greater than that of climbing stairways of equal angle and height. However, ramp use required less knee flexion than stair climbing and was easier from a biomechanical perspective.

Turner and Collins (1981) videotaped pedestrians walking on ramps at a stadium. By analyzing postural tilt and applying the data to biomechanical equations, they concluded that slopes greater than 1:3.3 would significantly change the walking pattern by limiting joint rotation.

In an examination of sloped and level walking, Buczek (1990) found that the range of motion of the ankle during stance phase was greatest when walking uphill. Not surprisingly, plantar flexor power and positive work during push-off were also greater for uphill than for downhill walking. In contrast, the type of grade did not significantly affect positive work, negative work, or power generation associated with the knee. While the participants in this study were young, healthy men, implications can be drawn for older adults. In particular, the decreased plantar flexor power noted by Woollacott (1993) and Judge, Davis, and Ounpuu (1996) may inhibit the ability of older people to use ramps.

A few studies reviewed by Sanford et al. (1994) reported anecdotal information regarding ramp use. One study found that residents and staff of a housing center for elderly adults were dissatisfied with the safety of ramps. In another study, older adults performed activities of daily living (ADLs; see Clark, Czaja, and Weber [1990]) in a model apartment. Although the apartment was accessible by both stairs and 1:12 ramps, "Ambulatory people with mobility impairments almost always chose to ascend the stairs" (Sanford et al., 1994, p. B$6)$.
Elderly people may prefer ramps over stairs for several reasons. Walking on a ramp requires less leg extensor power and less joint rotation than negotiating stairs. Gait patterns employed on ramps are similar to those used on a level surface, while gait patterns associated with stairs are different. On a ramp, the feet are closer to the walking surface during the swing phase of the stride, perhaps giving users an increased sense of safety. Ramps reduce the likelihood of trips and missteps (Jackson and Cohen, 1995). Most ramps have shallower slopes than stairs of the same total rise, so the cardiovascular cost of traversing a ramp may be less than that of negotiating a flight of stairs. This flatter slope may also make it easier to arrest a fall on a ramp than a fall on stairs.

Nevertheless, ramps are not without their problems. They may require greater postural and muscular control than stairs, particularly during descent (Sanford et al., 1994). Users of assistive devices such as canes, crutches, or crutch-tipped walkers may use a vaulting motion when negotiating ramps; older people and others with disabilities may not have sufficient stamina or upper-body strength to complete this motion (Sanford et al., 1994).

\section{SCOPE OF THE STUDY}

Although there is a large body of work regarding ramp use, few studies have evaluated ramp ambulation by older people, and no studies have been found which examine the kinematics of ramp ambulation with regard to ramp grades commonly encountered in public buildings. A two-phase study was conducted to address these neglected areas. The first part was a survey of ramp use by older people. The second part involved an experiment evaluating older people's abilities to traverse ramps of various slopes. This paper reports Phase I.

\section{SURVEY PURPOSE AND DEVELOPMENT}

The Phase I survey was conducted to describe characteristics of ramp use by older ambulant people, to establish a basis for ramp design recommendations, and to screen subjects for participation in the Phase II experiment.

Participants were questioned about their health, problems they have with stairs and ramps, and situations in which they choose a particular means of access. Questions were divided into four categories: demographics, health, falls, and ramp and stair use. Most of the questions followed a multiple-choice format (e.g., When going up, are you more likely to trip on a ramp or on stairs, or are they about the same?) For questions comparing ramps and stairs, respondents were instructed to consider going up or down one level. Responses to openended questions, such as those regarding reasons for using ramps or stairs, were recorded and later categorized for analysis. Respondents' voluntary comments also were recorded. 


\section{FINDINGS}

\section{Demographics}

Forty-three community-dwelling adults aged 57 to 95 participated in the survey. They were recruited from churches, a retirement home, University of Oklahoma faculty, and a lecture/discussion group. The mean age was 74.2 years, and 25 subjects were between the ages of 69 and 77. Thirty-one participants were women. All respondents reported the ability to complete the six activities of daily living without assistance. Most respondents (28) lived with spouses, family members, or a friend. Fourteen lived alone, and one lived with a full-time caretaker.

\section{Health and Physical Limitations}

Twenty-four participants considered their health better than that of their contemporaries. Three rated it worse, and 16 rated their health the same as that of others their age. Arthritis was a common complaint; $47 \%$ had arthritis in their lower extremities or spine. Two respondents occasionally used a walker. Two respondents regularly used a cane; four used a cane occasionally.

Thirty-four participants found it easy to walk $0.4 \mathrm{~km}(1 / 4$ mile) without stopping. Five rated this task as difficult; two said they could not walk $0.4 \mathrm{~km}$ without stopping, and one did not know.

Falls

Forty percent (17) of the respondents had fallen within the last year, and six had fallen more than once. Of the falls reported, only two were unexplained. Stairs were a common location for falls; seven respondents had fallen at least once on stairs, and several falls occurred when the respondent failed to notice a single step. Other environmental hazards, such as obstacles and slick pavement, constituted most of the remaining causes.

\section{Ramp and Stair Use}

Twenty-three respondents said they ascended ramps instead of stairs most of the time, and 14 said they ascended ramps some of the time. Similar numbers were reported for descent (see Table 1).

Table 1. Frequency of choosing ramps over stairs.

\begin{tabular}{cccc} 
& Most of the time & Some of the time & Rarely/Never \\
\hline Ascent & 23 & 14 & 6 \\
& $53 \%$ & $33 \%$ & $14 \%$ \\
Descent & 22 & 13 & \\
& $51 \%$ & $30 \%$ & 8 \\
\hline
\end{tabular}

In addition to frequency of use, participants compared ramps and stairs on several other dimensions: comfort, speed, and tendency to cause fatigue, loss of balance, tripping, and shortness of breath. Overall, respondents felt less fatigued, less likely to trip, and more comfortable when using ramps rather than stairs for ascending one level. Among respondents choosing ramps for ascent most of the time, comfort was the predominant factor and may have encompassed the other measures (see Table 2). Balance was also an important factor for frequent ramp users, although it was less important to respondents overall. When descending one level, balance, tripping, comfort, and speed were the strongest determinants of ramp use among respondents as a whole and among those choosing ramps for descent most of the time (see Table 3). Comfort, balance, and tripping were especially important to frequent ramp users.

Table 2. Reasons for choosing ramps over stairs for ascent.

\begin{tabular}{lccccc}
\hline & Less tiring & $\begin{array}{c}\text { Better } \\
\text { balance }\end{array}$ & $\begin{array}{c}\text { Less } \\
\text { tripping }\end{array}$ & $\begin{array}{c}\text { More } \\
\text { comfort }\end{array}$ & Faster \\
\hline All respondents & 25 & 19 & 28 & 26 & 19 \\
& $58 \%$ & $44 \%$ & $65 \%$ & $60 \%$ & $44 \%$ \\
Frequent & 18 & 16 & 16 & 22 & 15 \\
ramp users & $78 \%$ & $70 \%$ & $70 \%$ & $96 \%$ & $65 \%$ \\
\hline
\end{tabular}

Table 3. Reasons for choosing ramps over stairs for descent.

\begin{tabular}{lccccc} 
& Less tiring & $\begin{array}{c}\text { Better } \\
\text { balance }\end{array}$ & $\begin{array}{c}\text { Less } \\
\text { tripping }\end{array}$ & $\begin{array}{c}\text { More } \\
\text { comfort }\end{array}$ & Faster \\
All respondents & 13 & 27 & 29 & 29 & 24 \\
& $30 \%$ & $63 \%$ & $67 \%$ & $67 \%$ & $56 \%$ \\
Frequent & 11 & 18 & 18 & 20 & 17 \\
ramp users & $50 \%$ & $82 \%$ & $82 \%$ & $91 \%$ & $77 \%$ \\
\hline
\end{tabular}

Vision played a role in the decision to use ramps. Several people who wore bifocals or had limited vision chose ramps for descent because they had trouble seeing stair nosings.

In general, respondents indicated that descent (on both ramps and stairs) was more problematic, particularly in regard to balance and tripping. A few remarked that ramps sometimes caused them to descend too quickly.

\section{Respondents' Comments}

Some participants had a clear preference for stairs. Exercise was the most common reason for choosing stairs over ramps, but one cane user preferred stairs " because I'm 
more in control." Four people said their balance during descent was better on stairs.

Others preferred ramps. Several participants said they often chose ramps because they were less crowded and therefore faster. Limited range of motion was another common reason for choosing ramps. As one man remarked, "On a ramp, you can put your foot down flat. You have to make a bend to put your foot on stairs." Another person said she usually chose ramps "because my artificial knee doesn't have the range of motion of my normal knee."

Fear also played a role. One woman remarked, "I have never had a fall but [I use ramps because] I'm very afraid I might fall." A 71-year-old woman chose ramps because her daughter told her that older people should avoid stairs.

Handrails were important to many participants and often determined the choice of route. In the words of one respondent, "I just hold on. I get along so much better when there's a railing."

\section{CONCLUSIONS AND RECOMMENDATIONS}

Results from this survey presented several questions for further study, some of which were addressed in the Phase II experiment. For example, which ramp angle is most appropriate for older users? Do ramps present a tripping hazard, and, if so, which angles minimize this hazard? At what point does the angle interfere with a person's ability to control speed during descent? What are the ranges of motion of the knee and ankle during ramp use, and how do these compare with the ROMs reported in the literature regarding stair use? Is balance on ramps truly better than balance on stairs?

Several conclusions can be drawn from this survey. First and foremost, older people are not homogeneous in their preferences for ramps or stairs. Many determinants, including physical abilities, perceptions, and convenience, contribute to the choice of route.

While respondents choosing ramps most of the time usually cited specific reasons, those choosing ramps some of the time tended to rate ramps and stairs the same on most dimensions. For these people, convenience often determined the choice of route.

Preferences for ramps or stairs did not appear to be related to the ability to walk $0.4 \mathrm{~km}$ or the length of time a person could walk or stand. Interestingly, perceptions of personal health were not always indicative of the ability to walk $0.4 \mathrm{~km}$; the two respondents who could not walk this distance rated their health as better than that of their contemporaries, and one of the participants in worse health could easily walk $0.4 \mathrm{~km}$.

The most common complaint expressed by respondents was the absence of handrails on ramps and stairs. Although the ADAAG require only that one rail be provided, a better solution is to place rails on both sides of a ramp or stairway. For particularly wide access routes, a center rail may also be preferable. This would ensure that a handrail is usually within easy reach.

The ADAAG implicitly assume that a ramp accommodates everyone. In contrast, this study indicates that entrances should have both ramps and stairs so that people may use their preferred means of access.

\section{REFERENCES}

Buczek, F. L. (1990). Three-dimensional kinematics and kinetics of the ankle and knee joints during uphill, level, and downhill walking. Doctoral thesis. State College, PA: The Pennsylvania State University.

Clark, M. C., Czaja, S. J., and Weber, R. A. (1990). Older adults and daily living task profiles. Human Factors, 32, 557-550.

Corlett, E. N., Hutchinson, C., DeLugan, M. A., and Rogozenski, J. (1972). Ramps or stairs: The choice using physiological and biomechanic criteria. Applied Ergonomics, 3, 195-201.

Couch, R. H. (1992). Ramps not steps: A study of accessibility preferences. Journal of Rehabilitation, 58, 65-69.

Hawes, C., Rose, M., and Phillips, C. D. (1999). A national study of assisted living for the frail elderly. Executive summary: Results of a national survey of facilities. Myers Research Institute. Internet: aspe.hhs.gov/ daltcp/reports/facreses.htm.

Jackson, P. L., and Cohen, H. H. (1995). An in-depth investigation of 40 stairway accidents and the stair safety literature. Journal of Safety Research, 26, 151-159.

Judge, J. O., Davis, R. B., and Ounpuu, S. (1996). Step length reductions in advanced age: The role of ankle and hip kinetics. Journals of Gerontology, 51, M303-M312.

Sanford, J. A., Duncan, R., Guerette, P., Mace, R., Ostroff, E., Gupta, S., and Jo, L. (1994). A review of technical requirements for ramps. Task 1: An analysis of current accessibility standards and literature. Rateigh, NC: The Center for Accessible Housing, North Carolina State University.

Sanford, J. A., Story, M. F., and Jones, M. L. (1997). An analysis of the effects of ramp slope on people with mobility impairments. Assistive Technology, 9, 22-33.

Steinfeld, E., Schroeder, S., and Bishop, M. (1979). Accessible buildings for people with walking and reaching limitations. Washington, DC: U.S. Department of Housing and Urban Development, U.S. Government Printing Office.

Turner, G., and Collins, B. L. (1981). Pedestrian movement characteristics on building ramps. Washington, DC: National Bureau of Standards.

United States Access Board (1990). Americans with disabilities act accessibility guidelines. Internet: www.accessboard.gov/bfdg/adaag.htm.

U.S. Department of Health and Human Services, Administration on Aging (1996). Aging into the 21 st century, by J. Siegel. Internet:www.aoa.dhhs.gov/ aoa/stats/aging21/default.htm.

U.S. Department of Health and Human Services, Administration on Aging (1999). Profile of Older Americans: 1999. Internet: www.aoa.dhhs.gov/ aoa/stats/profile/default.htm.

Woollacott, M. H. (1993). Age-related changes in posture and movement. Journals of Gerontology, 48, special, 56-60. 